\title{
REINA POR UN DÍA: LA CONSTRUCCIÓN DE GÉNERO DURANTE EL FRANQUISMO
}

\author{
M. Àngels Francés Díez \\ angels.frances@ua.es \\ Universidad de Alicante
}

Recibido: 15-02-2012

Aceptado: 27-04-2013

\section{Resumen}

En este artículo nos proponemos ofrecer una visión diacrónica de la construcción de la identidad de género durante el franquismo y los años sesenta, centrándonos, principalmente, en el papel que los medios de comunicación representaron a la hora de conformar el modelo femenino de la época. Así pues, analizaremos las razones por las cuales el aparato ideológico del Régimen se centró especialmente en el despliegue de normas y definiciones de la que había de ser la nueva mujer española, veremos cómo contribuye la Iglesia en esta tarea y, también, el colectivo médico, la prensa escrita, la radio y la televisión. El recorrido acabará en la encrucijada que suponen los años sesenta y setenta, con la introducción de nuevos modelos femeninos que, en una amalgama imposible, conviven con los tradicionales.

Palabras clave: franquismo, modelo femenino, nueva mujer española, radio, televisión, prensa.

\begin{abstract}
In this article, we aim to offer a diachronic view of the construction of gender identity during the Franco's regime and the sixties, focusing primarily on the role that media represented in shaping the female model at that time. Thus, we analyze the reasons why the ideological apparatus of the regime concentrated particularly on the deployment of standards and definitions of what should be the new Spanish woman, also examining how the Church, the medical community, the press, radio and television contributed to this task. The analysis will end at the crossroads involving the sixties and seventies, with the introduction of new female models in a rather impossible combination with the traditional ones.
\end{abstract}

Keywords: Franco's regime, female model, new Spanish woman, radio, television, press. 


\section{Introducción}

Durante la dictadura franquista, los medios de comunicación contribuyeron poderosante a la construcción y difusión del modelo femenino basado en los roles de esposa y madre, al tiempo que ocultaban, menospreciaban o censuraban otras opciones vitales que pusieran en cuestión el reparto estanco de roles de género. Transmisores de un aparato ideológico construido por el Estado y la Iglesia, colaboraron con la educación segregada por sexos, la Sección Femenina de la Falange y el discurso de algunos representantes del colectivo médico en el diseño de la que debía ser la nueva mujer española. "Reina por un día", el programa de Televisión Española creado en 1964, resume el cielo al cual una afortunada mujer podía aspirar: una horas de excepción, en las que sueños como el viaje que el mísero sueldo de su marido no podía costear se hacían realidad, en las que su falta de poder real se tornaba posible por un tiempo efímero, parecido a aquél de los cuentos de hadas.

\section{La construcción de género en la posguerra: el modelo femenino}

Las mujeres que, durante la II República, habían participado en la construcción de un marco legal para la igualdad de derechos, al acabar la guerra se ven obligadas a marchar al exilio, ingresar en prisión ${ }^{1}$ o, simplemente, caen en un silencio profundo. Las mujeres, en un bando u otro, son las que sufren de una manera más directa y brutal el proyecto autoritario y patriarcal de la dictadura. De hecho, son utilizadas como pieza clave para la política franquista de dominio social y económico, con una legislación que establece un modelo femenino de esposa y madre. Sólo esta importancia de la mujer como pieza clave para la construcción de la nueva sociedad explica los ríos de tinta derramados en pro de la reeducación femenina, los esfuerzos de los aparatos represores del Estado para situarla en el lugar que le correspondía en el engranaje de la maquinaria.

Sin embargo, las mujeres no constituyen un colectivo homogéneo durante el franquismo. Entre ellas no sólo había diferencias de clase, de cultura y de trabajo, sino también el hecho de pertenecer al bando de los triunfadores o los vencidos. $\mathrm{M}^{\mathrm{a}}$ Carmen García-Nieto (2000) propone una clasificación que tiene en cuenta la respuesta de las mujeres en la política del Estado, distinguiendo tres núcleos principales: en primer lugar, un grupo de integración y consenso, formado por la mayoría de la población femenina — bajo la tutela oficial—, que con la implantación del capitalismo se benefició de un bienestar material cada vez mayor y aceptó el modelo de esposa y madre que satisfacía la organización patriarcal de la sociedad franquista.

\footnotetext{
${ }^{1}$ Giuliana di Febo (1979) constata que son alrededor de 30.000 las presas políticas entre 1939 y 1940, y cerca de mil las condenadas a muerte.
} 
En segundo lugar, encontraríamos el grupo de independencia y presencia en la sociedad que, sin cuestionar el modelo económico, buscan caminos y pautas de comportamiento que les permiten salir de casa. Son, por ejemplo, las que Carmen Martín Gaite (1987: 74) llama "chicas topolino", seguidoras del modelo norteamericano de mujer que llega con el cine; también las mujeres que, a través de la Iglesia, encuentran otras plataformas de presencia y de socialización (Acción Católica, las Congregaciones Marianas y otros movimientos apostólicos) y, finalmente, las que en los años sesenta y setenta se insertaron en el mercado de trabajo y la educación superior, a la búsqueda de caminos de independencia y de afirmación de la identidad. En tercer lugar situaríamos las otras mujeres, entre las que se encontraban las derrotadas - identificadas con la República durante la Guerra Civil—, que fueron víctimas de una cruel represión, las mujeres de la clase obrera y las capas populares de la sociedad, marcadas por el hambre, la miseria y el miedo, bajo la mirada vigilante de la Iglesia y de la policía, y las mujeres que, desde la clandestinidad, unas en la posguerra y otras en los años de crecimiento económico y crisis, participaron en la resistencia y, desde una acción de solidaridad, pasaron a defender la libertad para las mujeres desde los partidos políticos, las organizaciones sindicales y los movimientos feministas.

Dentro de este conjunto, cabe destacar la única organización de mujeres que ejerce un poder sin precedentes sobre la sociedad española de la posguerra: la Sección Femenina de la Falange $^{2}$. Con el apoyo del gobierno, las ideas de José Antonio Primo de Rivera y los modelos fascistas alemán e italiano, Pilar Primo de Rivera acumula en sus manos la responsabilidad y el poder de educar a la juventud femenina del país. El compromiso activo de la mujer en la vida pública, postula Pilar, se acaba con la guerra: su labor en la revolución era una "misión de ayuda, no es misión directora, porque esa sólo corresponde a los hombres" (Scanlon, 1986: 323). Así pues, se inicia una potente campaña para el retorno de la mujer a casa, donde tenía que llevar una vida mansa y callada de subordinación y sumisión al hombre. El deseo de igualarse era, en palabras de la dirigente de la Sección Femenina, "pedante, ridículo y camino seguro del fracaso como mujer": tocaba ser una "mujer de su tiempo", feliz en la maternidad, educando los hijos, demostrando un interés femenino por los asuntos de su hombre y proporcionándole un refugio tranquilo contra los azares de la vida pública (Scanlon, 1986: 324). Así pues, había que reeducar las mujeres y prepararlas para guiar la nueva generación, sin llegar, eso sí, a formar:

“[...] el tipo detestable de oradora. Nada más contrario a lo nuestro que la antigua mujer parlamentaria, desgañitándose en los escenarios para conseguir votos. Por el contrario, todos los días deberíamos dar gracias a Dios por habernos privado a la mayoría de las mujeres del don de la palabra, porque si lo tuviéramos, quién sabe si caeríamos en la vanidad de exigirlo por las plazas" (Posa, 1977: 125).

\footnotetext{
${ }^{2}$ José Antonio Primo de Rivera crea la Sección Femenina de la FET (Falange Española Tradicionalista) en 1934, y encarga su dirección a su hermana, Pilar Primo de Rivera, que desarrollará este cargo durante 43 años, hasta 1977. A partir de 1939 se convierte en una organización de masas —el número de afiliadas oscila entre las 11.000 que cita Giuliana di Febo (1979: 137) y las 580.000 que enumera Elena Posa (1977: 122).
} 
En este estado de cosas, el feminismo, evidentemente, es denigrado y atacado desde los más diversos argumentos. Pilar Primo de Rivera es el modelo a seguir, como explica la anónima titular de un consultorio sentimental recreado por Andrés Sopeña (1996: 212):

\begin{abstract}
"Desde aquella ya lejana primera respuesta, me he considerado humilde pero fervorosa colaboradora en la tarea enunciada por José Antonio de rodear de mayor dignidad humana y social a las funciones femeninas. Por eso no he sido feminista, como no lo fue, como no lo es Pilar".
\end{abstract}

El padre Delgado Capeáns es también muy explícito al respecto, cuando considera el feminismo la "bancarrota del honor y la dignidad de la joven" (Scanlon, 1986: 329). No es el único, sin embargo, que carga las tintas contra los aires igualitarios que caracterizaron la República, los cuales, según Maíllo,

“[...] hincharon las velas de aquel feminismo absurdo que iba desde la sufragista masculinizada y la heroína de novela ibseniana (que en lugar de hijos y amor a su hogar tenía conflictos espirituales) hasta la compañera marxista, desvinculada de su auténtico destino de mujer para entregarse con su eventual pareja a campañas de agitación y propaganda revolucionaria” (Sopeña, 1996: 70).

Incluso hay quien cree encontrar la fórmula que define la esencia de la mujer y reduce a filosofía barata las pretensiones de las feministas: en palabras de Vilariño, "jadjutorium simile sibi!" (Sopeña, 1996: 82), que viene a significar que la mujer ha sido creada para ser el auxilio del hombre, pero un auxilio similar a él, y esta misión de ayuda y apoyo, inherente a su naturaleza, ha de dirigir su existencia.

Para reeducar a las mujeres en la ideología del Régimen, la Sección Femenina se imbrica hábilmente en algunos espacios claves de la sociedad: la escuela, la universidad, los barrios populares e, incluso, el ámbito rural ${ }^{3}$. Junto con la Iglesia, controlan los libros de texto, los programas y materias de enseñanza ${ }^{4}$; en la universidad, los seminarios, las becas de estudio, las residencias y los cursos del Servicio Social, considerados indispensables para la formación de las estudiantes. De hecho, a través del Servicio Social, obligatorio para todas las mujeres

\footnotetext{
${ }^{3}$ En el campo, la Sección Femenina continua la tarea iniciada durante la guerra con la Hermandad de la Ciudad y el Campo (formada por delegadas que se inserían entre las campesinas para instruirlas en la cultura y la ideología del régimen), y en 1940 crea las Escuelas Granjas para formar al profesorado que debía llevar a cabo esta misión. En este ámbito, la Sección Femenina exaltaba los valores tradicionales de la tierra; evidentemente, los problemas derivados de la desoladora realidad del sector agrario español, que recaen especialmente sobre las mujeres, oprimidas por la doble carga de la casa y el campo, eran obviados en sus discursos. Véase Posa (1977: 129) y Di Febo (1979: 143-144).

${ }^{4}$ Como se reimplanta la segregación por sexos, se insertan asignaturas específicas para las niñas, que deben ser preparadas para los papeles de madres y esposas o, quizás, trabajadoras subalternas en alguna empresa dirigida por hombres. Los niños, en cambio, eran orientados a desarrollar un papel dirigente en la sociedad (en el gobierno, el ejército, la administración o, en última instancia, en su propia familia, donde la autoridad paterna debía ser indiscutible). La soltería no solía considerarse una libre opción para las mujeres, sino el síntoma de un fracaso. Véase Lafuente (2003: 147-148). En este contexto, el control de la educación física era fundamental. Según Pilar Primo de Rivera, "la educación física, que no cabe duda que tiene sus peligros, tiene también inmensas ventajas, como son la disciplina colectiva, la unidad cuando hacen ejercicios juntas varias provincias [...]" (Posa, 1977: 128).
} 
(excepto las casadas, las monjas, las viudas, las huérfanas de guerra y las que tenían ocho hermanos solteros) y necesario para poder estudiar una carrera, trabajar en la administración pública o en fábricas del Estado, obtener el carné de conducir o pertenecer a cualquier asociación cultural o recreativa, la Sección Femenina ejercía su proselitismo al amparo de la ley ${ }^{5}$.

Así pues, los principios del nacionalcatolicismo impregnan todos los ámbitos de la vida cotidiana, y visten de transcendentalidad áreas tan prosaicas como la indumentaria o el tiempo de ocio. El discurso dominante, centrado principalmente en la regulación del comportamiento de las mujeres jóvenes, utiliza el esquema conceptual de la religión católica para definirlas en parámetros de género, basándose en la teoría bíblica en torno a la Génesis y el tema de la procreación, destinada a ser el fin último de la mujer española. La biología se convierte así en destino: el sexo es medida y causa última del edificio cultural construido. La sexualidad femenina, pues, pasa a tener un papel primordial para el mantenimiento la cohesión social, y debe ser regulada estrictamente para asegurarlo ${ }^{6}$.

La cosmología nacional-católica percibe a la mujer como más débil, menos preparada para afrontar la vida, mientras que su esencia emocional le resta capacidad para discernir. Por ello, las mujeres necesitan ser tuteladas y más aún en relación a la sexualidad, que es insaciable e impura; solamente la procreación, la maternidad en el contexto del matrimonio, las redime de alguna manera. Según esta definición, la mujer es extremadamente vulnerable, ya que su debilidad implica que ofrezca poca resistencia a las tentaciones del pecado.

El diseño del modelo femenino franquista empieza en la infancia, según los principios del nacionalcatolicismo, más estricto para las niñas. La educación recibida en la escuela, que las prepara para desarrollar el papel al que están destinadas, se completa durante el tiempo de ocio con las muñecas de trapo, las peponas y, en el caso de las más afortunadas, la Mariquita Pérez ${ }^{7}$. Las lecturas de los adolescentes de la época también son manejadas con cuidado, tanto para las mujeres como para los hombres. Carmen Alcalde (1996: 113-117) enumera algunas:

\footnotetext{
${ }^{5}$ A partir de 1940, el Servicio Social es obligatorio durante seis meses; la ley de 26 de noviembre de 1946 lo hace extensible también a las trabajadoras de las fábricas, que debían asistir a los cursos de Sección Femenina (sobre cocina, gastronomía, puericultura, religión, historia de España, etc.) dos horas al día durante seis meses. Véase Di Febo (1979: 141).

6 Esta construcción es similar a la efectuada en otras sociedades mediterráneas, definida fundamentalmente en relación a la sexualidad femenina y cristalizada en el complejo de honor y vergüenza (Roca, 1996: 43).

${ }^{7}$ Las creadoras de la muñeca, Leonor Coello de Portugal y Pilar Luca de Tena, supieron valorar la existencia de todo un sector de la sociedad española, enriquecida tras la guerra, que podía permitirse el lujo de comprarla y exhibir su posición económica. La empresa es, según Lafuente (2003: 178), el primer ejemplo de negocio neto en la España del estraperlo. La clave de su éxito, según Carmen Martín Gaite (1987: 121), es "la explotación del prurito competitivo de elegancia y estilo agazapado, como estímulo de superaciones, bajo el estático ideal de la mujer hacendosa." Cada temporada, esta muñeca saca a la luz toda una colección de vestidos y complementos, y a su alrededor nacen publicaciones, clubes infantiles y programas de radio. Es la primera de toda una serie de muñecas (Gisela, con los hermanitos Guni y Lili; Cayetana, con Manolín y Pitusa) que difunden un determinado modelo de mujer definida por la indumentaria y la vocación doméstica.
} 
"Flechas y Pelayos, Margaritas, Roberto Alcázar (diseño del héroe sospechosamente parecido a José Antonio) y, luego, Roberto Alcázar y Pedrín, que van por la vida arrasando a los malos, es decir a los antihéroes, El guerrero del antifaz, ${ }^{8}$ El hombre enmascarado y su amor platónico y virginal por Diana. Y las Hazañas bélicas [...]. Y con la inefable Florita sólo para mujeres y el entrañable $T B O$ llegaremos a la mayoría de edad".

Estas obras épicas y sentimentales se combinan, en las escuelas femeninas, con las vidas de santos y santas (San Francisco de Asís, Santa Teresa de Jesús) y de mujeres que, excepcionalmente, habían destacado a lo largo de la historia, como Isabel la Católica o Agustina de Aragón9. Recomiendan la lectura de autores como Concha Espina, Fernán Caballero, Concordia Merello, Pérez Lugín, etc. Son desaconsejados, por el contrario, los autores crudos e inmorales como Pedro Mata, pero también La regenta, calificada como una admirable novela, pero no apta para señoritas. Carmen Martín Gaite (1987: 149) recoge los comentarios de un artículo de la época, encaminados a dirigir las lecturas de las adolescentes, que concluyen advirtiéndolas de los peligros de la modernidad para el espíritu: "Créame, amiga mía, aprovéchese de todos los adelantos de la civilización en cuanto a lo físico: el teléfono, la radio, el automóvil, pero en cuanto al espíritu, déjele con miriñaque y polisón, cuídele como a un niño, trátele como a un novio".

Los y las más contestatarias, sin embargo, que mantienen una cierta independencia ideológica en escuelas afines a la República, acceden a los libros de la editorial Bruguera, los cuentos y las novelas de Salgari, Julio Verne y las Mujercitas de Louise May Alcott, que la escritora Montserrat Roig (1972: 17) recuerda en su versión cinematográfica: "las adolescentes saboreaban las difusas mieles del matriarcado con películas como Mujercitas, en la cual el hombre sólo actuaba epidérmicamente" ${ }^{, 10}$.

Andrés Sopeña repasa, en La morena de la copla. La condición de la mujer en el reciente pasado (1996), algunos de los documentos que destacados miembros de la comunidad eclesiástica publican con la intención de regular el comportamiento de las jóvenes españolas, con títulos como Normas de decencia cristiana (Pla y Deniel) y Las modas y el lujo (Isidro Gomà). Con una ironía que muestra la parte menos patética de las maniobras de manipulación moral y social efectuadas por la Iglesia franquista, Sopeña comenta fragmentos como el siguiente, relacionados con la moda femenina:

${ }^{8}$ El guerrero del antifaz narra las historias de un héroe que, de aventura en aventura, a menudo encontraba misteriosas mujeres que lo tientan "entre risotadas, gasas flotantes y velos transparentes" (Martín Gaite, 1987: 100). El amor del guerrero, sin embargo, es para la paciente condesa Ana María, que le espera entre suspiros hasta que vuelva. A Carmen Martín Gaite, el planteamiento le recuerda los largos noviazgos de la posguerra y los héroes que, mientras preparaban oposiciones para tener un futuro y casarse con la condesa Ana María de turno, no se resistían del todo a los amores impuros que la prostitución les facilitaba.

${ }^{9}$ El papel ejemplar de estas mujeres, sin embargo, no debía ser imitado por las aspirantes a madres y esposas; más bien, se ofrecían como modelo de valor y audacia para los hombres, los únicos que estaban destinados a desarrollar estas virtudes. Véase Carmen Martín Gaite (1987: 150).

${ }^{10}$ Alcalde (1996: 117) la recuerda también: "La película fue en España para las mujeres una entrada de aire fresco en el que con toda naturalidad se reconocía la libertad de la mujer como un ser humano en competición con el hombre." 
“¿Qué modas más indignas, tan atentatorias al pudor! ¡Pierna al aire hasta el muslo, brazos al descubierto hasta cerca del sobaco, escotes en el pecho y en la espalda, vestidos ceñidos al cuerpo de un modo inverecundo! ¡Casi van peor que desnudas!” (Ayala, citado por Sopeña, 1996: 158).

También sobre el mundo de los cosméticos se pronuncian sacerdotes como Massimiliano Mazzel que, tras vincular la costumbre femenina del maquillaje a épocas históricas caracterizadas por crisis morales y políticas ${ }^{11}$, enumera el tipo de pecado que implica, según los casos:

"I El pintarse es, en general, pecado grave si se hace para fomentar la impureza.

II Es pecado venial si se hace por vanagloria o para fingir una hermosura de que se carece.

III No es pecado si hay una causa proporcionada, por ejemplo, ocultar la fealdad" (Mazzel, citado por Sopeña, 1996: 160).

Según estos expertos en la materia, el problema radica no sólo en la posible condenación de la joven atrevida que se exhibe impúdicamente, sino en las consecuencias para los que la contemplan. Según Enciso:

"El vestido deshonesto es la ruina de la moral pública. Cubierta con él, la mujer se constituye en sacerdotisa del culto a la carne, y a su paso por la calle va encendiendo en los que la admiran la llama de la sensualidad, desatando las repugnantes pasiones que bullen en los más bajos fondos de lo humano, despertando pensamientos impuros, excitando deseos deshonestos y lanzando a muchos por la pendiente de la impureza, por la que se precipitan rápidamente en el sucio abismo de la vida reptil" (Enciso, citado por Sopeña, 1996: 170).

La regulación de todas estas prosaicas cuestiones se encamina, básicamente, a definir y dibujar lo que debe ser la española en esencia, a guiarla para que llegue a ser el modelo de mujer ideal ${ }^{12}$. Maíllo resume el cúmulo de virtudes que atesora la representante de la raza hispánica en:

"Una elegancia innata, no aprendida, que va desde el porte y el continente hasta las manifestaciones más menudas y cotidianas; una virtud natural, heredada, que no es producto de algo preconcebido, de artificialismo ni de pose; un poder de intuición inimitable y una castidad esencial, biológica, diríamos, forman parte de las prendas espontáneas de la mujer española[...]" (Sopeña, 1996: 187).

Las citas que podríamos aportar aquí son numerosas, todas elaboradas con una retórica similar. De hecho, sorprende la cantidad de publicaciones que se ocupan del tema en cuestión durante los primeros años de posguerra. En su libro, Sopeña las filtra con un

\footnotetext{
11 "La moda de pintarse no es cosa nueva. Ya en otros tiempos la usó la mujer, pero — hecho notablesiempre en periodos de decadencia" (Sopeña, 1996: 160).

12 "La mujer española, casta, cristiana y buena, selecta por instinto y dotada de una ingente capacidad de sacrificio, es el reservorio providencial de las mejores tradiciones de nuestra raza", según el padre Maíllo (Sopeña, 1996: 186).
} 
fino sentido del humor, pero no puede dejar de constatar la crueldad con que estos escritos podían llegar a coartar la libertad de las personas:

"Sin embargo, haría pero que muy mal quien concluyera de lo hasta ahora dicho, que tan talares personajes no tienen otro norte que la prohibición indiscriminada, absurda y constante, a poder ser, amedrentando; que para ello, usan y abusan de su ascendiente, de su posición de privilegio; y que sólo una misoginia enfermiza puede engendrar una moral, tan pacata y ridícula, como ruin" (Sopeña, 1996: 180).

Algunos profesionales de psicología se dedicaron también a establecer las bases científicas que justificaron la construcción de los estereotipos de género vigentes durante la posguerra. Es el caso, por ejemplo, de Carlos Muñoz Espinalt, quien publica un libro titulado Psicología de la mujer, donde la describe según diversas tipologías o tonos psicológicos. Destacan varios, etiquetados con las letras del alfabeto. Andrés Sopeña (1996: 46) comenta el tono más común de la siguiente manera:

\footnotetext{
"Al parecer, uno de los tonos más extendidos entre las españolas es el clasificado por este hombre como $\mathrm{AB}$, que "responde al tipo femenino que los hombres definen de manera escueta, pero harto significativa: es una mujer para casarse"; que eso se nota en lo pulcra, ordenada, equilibrada, sencilla, íntegra y prudente que es la mujer. También da una pista el hecho de que ella misma considera que "lo ideal para una mujer es ser señora de un hogar confortable".
}

La antítesis de este prototipo es la señora $\mathrm{CD}$, que asusta a los hombres con la falta de timidez y el temperamento erótico ${ }^{13}$. La mujer tipo ACDE, en cambio, conjuga los dos extremos en una especie de doble personalidad: acumula algunas de las características de la mujer ideal pero le faltan después algunas otras, desviación que la conduce a despreciar al marido y renegar de su papel como esposa y madre. La mujer ABCD "responde al tipo femenino que 'da la impresión de que ha nacido para casarse con un hombre de mucho rango social', lo que puede lo menos quiere decir que no es tonta" (Sopeña, 1996: 54). Finalmente, el ABCDE, que contesta que sí a todas las preguntas del cuestionario de Muñoz, es calificada de camaleónica, ya que tiene una singular capacidad de adaptación y un carácter que varía mucho según las circunstancias.

\section{El papel de los medios de comunicación}

En la propagación del modelo femenino franquista colaboran también medios de comunicación como la radio y las revistas de la época, que con las novelas y la prensa rosa, los seriales radiofónicos y los consultorios sentimentales "contribuyeron de modo

\footnotetext{
${ }^{13}$ Véase Sopeña (1996: 49). Podemos identificar este prototipo con el de la vamp del cine.
} 
poderoso, y más hábil que las organizaciones del régimen, a configurar el carácter débil y dependiente en toda una generación de jóvenes españolas” (Larumbe, 2004: 21).

En efecto, la euforia de la sociedad de consumo propicia la aparición de revistas pensadas para las mujeres ${ }^{14}$ con un contenido específico sobre moda, cosmética, jardinería y decoración. Se excluyen otros contenidos (temas laborales, culturales, etc.) porque "la conquista de la gloria, y la lucha por labrarse un porvenir se consideraban indignos de una publicación dirigida a distraer los ocios de las futuras mujeres" (Martín Gaite, 1987: 98). Títulos como Cristal (1960), Maniquí (1960-1965), Femenino (1962-1964), Club Fémina (1962-1964), Telva (1963), Mía (1964-1965), Ella (1965), Delta (1965) y Miss (1966) cumplen una función claramente identificada con la dictadura, es decir, tienen el objetivo de "mantener a la mujer apartada de todo tipo de inquietud social, laboral o política, y relegarla al único puesto que le confíe este régimen, el hogar" (Blas, 1999: 342) ${ }^{15}$.

El panorama de publicaciones para las mujeres se completa con las novelas $\operatorname{rosa}^{16} \mathrm{y}$ las fotonovelas. El arquetipo de la joven en busca de marido, que normalmente alcanzaba este objetivo y se dedicaba a vivir una feliz existencia a su lado y rodeada de una gran cantidad de hijos, se transmite con eficacia a través de las páginas de las novelas de Corín Tellado, Concha Linares y Luisa María Linares. Paralelamente, la idea de la soltería toma la forma de un estigma:

"La que "iba para solterona" solía ser detectada por cierta intemperancia de carácter, por su intransigencia o por su inconformismo. Analizar las cosas con crudeza o satíricamente no parecía muy aconsejable para la chica que quisiera "sacar novio". Se les pedía ingenuidad, credulidad, fe ciega" (Martín Gaite, 1987: 38).

El estereotipo de la solterona ya mayor, rancia y cursi, estimulaba la idea de la dependencia del hombre como la única felicidad legítima e idónea para la mujer. Sólo la vocación religiosa podía desviar a la joven de la finalidad matrimonial sin perjudicar seriamente su prestigio social. Más bien al contrario, “el tema de la jovencita que se metía a monja, renunciando a los placeres del mundo mediante la ofrenda simbólica de su mata de pelo, se exaltaba como algo grandioso y digno de narración” (Martín Gaite, 1987: 37).

\footnotetext{
${ }^{14}$ La mayoría de estas revistas estaban dirigidas por mujeres, entre las que cabe destacar María Fernanda G. de Nadal (Cristal), Pilar Salcedo (Telva) y María Rosa Garrido (Ella). También incluían colaboraciones de mujeres periodistas y escritoras. Véase Blas (1999: 342).

${ }^{15}$ Las revistas que se aventuran a publicar algún contenido de actualidad o interés social, como Hogar 2000, tienen serios problemas con la Administración. La prensa del corazón, que alcanza una enorme difusión durante esta década y las siguientes, ofrece los líos sentimentales de las famosas con profusión de fotografías a todo color, siempre reforzando valores de la mujer tradicional como el amor, el matrimonio, los hijos, etc.

${ }^{16}$ A pesar del éxito de ventas, el género rosa no gozaba de muy buena fama en el panorama literario del momento, ni siquiera entre los mismos autores que el cultivaban: Carmen de Icaza y Concha Linares protestaron porque la editorial subtitulaba sus obras con el color en cuestión. Véase Carmen Martín Gaite (1987: 148).
} 
Asimismo, las ondas radiofónicas se convierten en el medio idóneo para difundir la doctrina del régimen, explícita, sobre todo, en los programas dirigidos a una audiencia femenina representada por el prototipo de "la señora Maruja", ama de casa, analfabeta, con poca o ninguna independencia. Son los años triunfales de Concha Piquer, Juanita Reina, Manolo Caracol, Lola Flores, Imperio Argentina, Estrellita Castro, Juanito Valderrama, etc. Las letras de sus canciones, "verdaderos dramas en veinte líneas" (Blas, 1999: 371), llenan los espacios de los libros que no leen la mayor parte de las españolas ${ }^{17}$. Evidentemente, la información general era competencia exclusiva de RNE: todas las emisoras estaban obligadas a conectar a la hora del parte, nombre popular que recibía el Diario hablado de la época ${ }^{18}$. Pero los programas estrella de la radio fueron los seriales, creados por Guillermo Sautier Casaseca, vigilados a conciencia por la censura porque las historias siempre estuvieron dentro de los principios ideológicos que Franco quería para el país. El impacto de seriales como Ama Rosa, La segunda esposa o Simplemente María se prolonga hasta la década de los setenta ${ }^{19}$. Consultorios sentimentales como el de Marta Regina o Elena Francis ${ }^{20}$ refuerzan esta idea, recomendando pureza y resignación cuando las historias de la vida real no resultaban tan idílicas como las de ficción. Resulta curioso, sin embargo, que las dos personas que durante tanto tiempo aconsejaron las desorientadas oyentes fueron dos hombres:

\begin{abstract}
“Marta Regina era un 'barbado abogado, muy lírico y sentido', y los parlamentos de doña Elena Francis los escribía Juan Soto aunque la voz era de Maruja Fernández. Puede que lo que sucediera es que, en el régimen, ni siquiera se podía aceptar que la mujer pudiera aconsejar a otras mujeres, no fuera a ser que les recomendara la rebelión" (Blas, 1999: $378)^{21}$.
\end{abstract}

Televisión Española se inaugura en 1956 y se convierte en la nueva arma política del Régimen, ya que promete velar por la ortodoxia religiosa y los ideales del Movimiento Nacional e invade rápidamente todas las salas de estar del país. La mayor parte de las

\footnotetext{
${ }^{17}$ A esta programación habría que añadir espacios música clásica o zarzuela, de cocina y religiosos, aderezados con un poco de publicidad.

${ }^{18}$ Hasta el 1977 no se concedió la libertad de información en las emisoras. Mientras tanto, muchos españoles intentaban sintonizar Radio Moscú, Radio Praga, Radio París o la radio más emblemática del exilio español, Radio España Independiente, Estación Pirenaica, que había comenzado a emitir en 1941.

${ }^{19}$ Los temas que abundan son el de la pecadora redimida por la maternidad, la joven pobre estimada para un hombre rico y bueno que acaba casándose con ella por ser honesta y virtuosa, etc.

${ }^{20}$ Las emisiones del consultorio, creado por la empresaria barcelonesa Francisca Bes Calvet, comienzan en 1947 y se prolongan hasta los años de la Transición. Fue un auténtico fenómeno sociológico durante varias generaciones. Puede consultar la historia en Soto (1996).

${ }^{21}$ Es probable que la monótona repetición de estereotipos que se respiraba en estos consultorios provocara las suspicacias de no pocas lectoras. Andrés Sopeña (1996: 204) reproduce la respuesta de una consejera sentimental a una airada feminista: "Y también comprendo tu enfado hacia la labor de este consultorio, y para conmigo. Creo, no obstante, que me concedes una importancia excesiva a mí y una influencia desproporcionada a esta humilde sección. Eso sí, me he reído con ganas con tus sospechas de que yo pudiera ser un hombre. ¡Qué imaginación tienes, hija mía!’ Para más información sobre la historia de la radio en España, véase Díaz (1994).
} 
mujeres que colaboran en este nuevo medio lo hacen cara al público, aportando su rostro a textos que escribían hombres. El éxito de programas como "Reina por un día", que recrea "el cuento de La Cenicienta, haciendo realidad el sueño de cualquier anónima ama de casa" (Blas, 1999: 395), nos da una idea del modelo de mujer a que la televisión ponía voz e imagen. En 1965, el segundo canal (el UHF) diversifica la oferta de programación, dando un tono cultural.

Con todo, tanto en la radio como en la televisión hubo mujeres que desarrollaron trabajos de realización y montaje detrás de los micrófonos. Ahora bien, sus nombres "han quedado ilegibles en los títulos de créditos de los programas" (Blas, 1999: 397). En los medios de comunicación de la época, las mujeres se veían sometidas a las mismas discriminaciones que en el resto de ámbitos laborales ${ }^{22}$.

En la industria cinematográfica, el panorama resultaba igual de desolador. El título de la primera película que se rodó en España, La salida de la misa de la Virgen del Pilar de Zaragoza, revela hasta qué punto las materias religiosas, patrióticas o costumbristas marcan el cine franquista, operación necesaria, por otra parte, para ofrecer una determinada visión de la realidad (Roca, 1996: 97).

En el cine patrocinado por el Régimen se proyectan algunos de los elementos configuradores del discurso dominante de posguerra: la irracionalidad, la exaltación de la ley, el militarismo, la sumisión al destino, la religiosidad, el andalucismo folclórico, etc. Alfredo Mayo se convierte en el prototipo de actor del período; abundan los papeles épicos en títulos como Harker, Escuadrilla (1941); A mí la legión y Raza (1942), el guión fue escrito por el propio Franco bajo el seudónimo de Jaime de Andrade. Otros títulos, como La Leona de Castilla o Alba de América, representan la temática histórica o religiosa. En cuanto a los modelos femeninos, Aurora Bautista, con "legiones de tonadilleras, gitanas con peineta y mantón, rostros varoniles con gorra militar o golilla y burguesas de escote discreto y honesto compartían cartelera con aquellas otras películas y actores, tan distintos, de la 'peligrosa' cinematografía americana" (Roca, 1996: 98).

Así, los directores de cine de los años cuarenta muestran los modelos sociales que interesan al régimen y niegan cualquier otra mirada histórica o social. Las películas se exhiben en salas donde es obligatoria la proyección del NO-DO, noticiario objetivo al servicio de la política educativa del Gobierno.

Sin embargo, la precaria industria española no podía competir con Hollywood, idílico y alejado del mundo real y cotidiano, que facilitaba la huida. De hecho, la producción estadounidense fue aumentando su presencia en cartel a partir de los años cincuenta, a pesar de la airada oposición de la Iglesia, que veía una fuente de modelos de moral más que dudosa y opuesta a los principios defendidos por el Régimen.

\footnotetext{
${ }^{22}$ Véase el estudio de Isabel Blas (1999) sobre la participación de las mujeres en los medios de comunicación durante los años del franquismo y la Transición. Para más información, véase también el libro de Lorenzo Díaz (1994).
} 
Rita Hayworth, Gilda, recupera para el cine el papel de vamp, tan habitual en algunas películas de los años treinta protagonizadas por Marlene Dietrich y Greta Garbo; Hollywood subvierte el discurso dominante ofreciendo a la sociedad española una vía de escape de la dura realidad ${ }^{23}$. La exaltación del amor romántico proporcionaba a las espectadoras príncipes azules con el rostro de Gary Cooper, Gregory Peck o Lawrence Olivier. A través de la conversación simbólica con el filme, podían aflorar los deseos y las fobias particulares de un público que en el marco de la sociedad de posguerra no encontraba las vías oportunas para expresarse de forma libre y desinhibida:

“Todo allí favorece la caída: la oscuridad, los aplausos, que más audaces en la sombra, subrayan los pasajes escabrosos, la compañía, la cinta, mucho más peligrosa que la lectura. Leer una novela de Zola supone tiempo (iy paciencia!) para recorrer 500 páginas. Al paso que en el cine el modo de percibir es intuitivo y rápido, ya que basta abrir los ojos" (Roca, 1996: 93).

Así, el cine se convierte pronto en un fenómeno de masas. Conscientes de que no podían prohibirlo, las autoridades del Régimen se aplicaron a edificar la censura ${ }^{24}$, que operó sobre el contenido político de las películas y sobre las escenas y los temas que más atentaban contra la moral católica ${ }^{25}$.

Si el cine - el estadounidense, sobre todo - era motivo de las más airadas diatribas por parte de las autoridades franquistas, otras formas de diversión, como el baile, también eran representadas como uno de los focos de infección que reclama con mayor firmeza la acción terapéutica del discurso dominante ${ }^{26}$.

Finalmente, cabe decir que el teatro experimentó un auténtico apogeo, sobre todo en la inmediata posguerra. Como actividad patrocinada por la Iglesia, parecía la alternativa menos dañina moralmente, porque se podía controlar con facilidad:

\footnotetext{
${ }^{23}$ En esta argumentación, Jordi Roca (1996: 97) es consciente de que el cine de evasión no hace más que reforzar los valores morales dominantes de la sociedad; ahora bien, en el panorama desolador de la posguerra española, dominado por una férrea represión, esta muestra de otras realidades provocaba no pocas reacciones entre los espectadores, ávidos de novedades.

${ }^{24}$ El Estado instauraba, en este sentido, varias disposiciones legales, que obligaban a las salas a calificar las películas mediante categorías como "recomendable para menores", "tolerada para menores", "autorizada", etc. Y por si este control no fuera poco, la Iglesia desplegó su propio sistema de clasificación para orientar al público. Su intención, sin embargo, no era aprobar ni recomendar ningún título en concreto: de esta actitud cabía deducir que el cine era peligroso siempre y, por tanto, también inconveniente. La normativa más segura era, según los círculos católicos, la condena sistemática y acrítica.

25 "Besos acortados, mutilación de escenas eróticas, matrimonios convertidos en hermanos, el caso del personaje devorado por un tigre imaginario con el fin de encubrir una relación adúltera o el de aquel otro que por obra y gracia del doblaje se declaraba al caballo... son tan sólo algunas pinceladas del rico anecdotario de la historia de la censura cinematográfica española de la época" (Roca, 1996: 99).

${ }^{26}$ Los más perversos, según estos alarmados oradores, eran el tango, el fox-trot, el onestep, el two-step, el swing y el bugui-bugui, que no obstante sonaban sin descanso en las verbenas de los pueblos y en los guateques, una especie de fiestas caseras que se van a generalizar a partir de los años cincuenta.
} 
"En primer lugar porque permite escoger oportunamente las obras pertinentes para ser representadas, y en segundo lugar porque la dinámica que caracteriza el montaje de una escenificación cualquiera obligaba a dedicarle tiempo, hasta el punto de llegar a ocupar la práctica totalidad del tiempo libre" (Roca, 1996: 102).

A pesar de todas estas estrategias de control sobre la construcción de género en la posguerra, que relegaban a las mujeres a un segundo plano en todos los ámbitos y les vedaba el paso, sobre todo, en el terreno público, no sería justo acabar este apartado sin mencionar algunos nombres femeninos que desafiaron el silencio impuesto y accedieron a la palestra. Isaías Lafuente (2003: 172) utiliza una frase de Pilar Primo de Rivera, "las mujeres no descubren nada: les falta, desde luego, el talento creador", para pasar a hablar de las mujeres que, en este contexto reaccionario y gris, hicieron visible su talento creador. El ámbito de los premios literarios es, posiblemente, la mejor prueba: en 1945, una autora barcelonesa desconocida, Carmen Laforet, gana, con su primera novela, Nada, el premio Nadal. Como explica Inmaculada de la Fuente (2002: 12), "ninguna palabra podría haber nombrado mejor el paisaje físico y moral de aquellos días de posguerra en los que las heridas de la contienda permanecían aún abiertas y ganadores y vencidos buscaban algo parecido al olvido." No sólo resultaba insólito que una mujer triunfara en la literatura - o en cualquier otro ámbito-; aún era más sorprendente que lo hiciera con una novela de vacío y soledad, ambientada en la Barcelona de los años cuarenta, que escandalizó a buena parte de la burguesía de la ciudad. Pero no fue la única voz de mujer que protagonizó la vida literaria del momento: en 1953 Dolores Medio gana el Nadal con Nosotros, los Rivero; cuatro años después es Carmen Martín Gaite quien recibe el galardón con Entre visillos y, en 1959, Primera memoria, de Ana María Matute, acaba de perfilar este panorama de premios otorgados a escritoras ${ }^{27}$ pese a la censura y las campañas de la Sección Femenina.

Estas escritoras no fueron las únicas pioneras del momento en acceder a ámbitos vedados para ellas: hay que destacar, también, las figuras excepcionales de Ana Mariscal (realizadora cinematográfica), Pilar Miró (directora y realizadora), Ángeles Galina (catedrática de Historia de la Pedagogía en la Universidad de Madrid y, más tarde, directora general de Enseñanza Media), Josefina Carabias (la primera corresponsal de la prensa española en el extranjero), Margarita Salas (investigadora), Esther Tusquets (editora), y otras que desafiaron la ideología dominante y se hicieron un lugar en la vida pública del momento ${ }^{28}$. Eran, sin embargo, fenómenos aislados aún, hasta que los cambios socioeconómicos de los años sesenta abrieron nuevas perspectivas para la sociedad en general y para las mujeres en particular.

\footnotetext{
${ }^{27}$ Mientras tanto, en el exilio, escritoras como Mercè Rodoreda, María Zambrano o Rosa Chacel continúan creando, pero sus voces no son escuchadas en la península hasta que no vuelven.

${ }^{28}$ Para más información sobre otras españolas emprendedoras en la posguerra, véase Lafuente (2003: 172-179).
} 


\section{Confluencia de tradición y renovación: la juventud}

El surgimiento del inconformismo entre las capas juveniles fue unido a la evolución de la oposición política antifranquista. La generación del $68^{29}$, formada principalmente por jóvenes universitarios, protagoniza un movimiento cultural y político importado, en parte, de las revueltas estudiantiles francesas y de la contracultura norteamericana, y adaptado a un medio muy característico, el régimen dictatorial, sustentado por fuertes medidas de represión en el ámbito legislativo y el moral.

La confluencia de los valores tradicionales de la sociedad española, exaltados hasta el paroxismo por la propaganda franquista, y las formas nuevas, visibles, que llegan con el turismo y el cine y rompen con lo establecido, condicionan el proceso de cambio de hábitos y actitudes, que se revela lento y lleno de conflictos. El choque de un sistema patriarcal y autoritario, con unas pautas culturales y religiosas específicas, con los aires contraculturales que llegan desde Europa y Estados Unidos provoca una especie de doble moral que confunde la sociedad del momento. Como explica Carmen Martín Gaite (1987: 30):

"Se trataba, en definitiva, de la oposición entre dos mundos y dos morales. Norteamérica,
país en progresiva expansión económica, llevaba años elaborando mitos de bienestar e
independencia que exportaba a Europa, principalmente a través de su boyante industria
cinematográfica. El foco de fascinación mundial, que en las primeras décadas del siglo XX
emanaba de Francia y dictaba la moda desde la "Ville Lumière", se había ido desplazando a
la antorcha de la estatua de la Libertad".

Con el eslogan "España es diferente", el Ministerio de Información y Turismo lanzó, en 1963, una campaña internacional que pretendía potenciar el turismo en el país, mostrando sólo la cara amable de la dictadura ${ }^{30}$. Con el turismo llega lo que la Iglesia y la cultura dominantes observan con preocupación como una muestra de la crisis del modelo familiar y la escala de valores tradicional: la revolución sexual, estrechamente relacionada también con la aparición de la píldora anticonceptiva en las farmacias españolas, en el año 1964. Primero fueron las mujeres más informadas; después, gracias al boca a oreja, el uso de este método se extendió rápidamente. Cuando se despenalizó el consumo de anticonceptivos, en 1978, ya eran 800.000 las mujeres que usaban la píldora en España.

\footnotetext{
${ }^{29}$ Según Carles Santacana (1998:1 82), “és un lloc comú situar l’any 1968 com una fita clara entre dues etapes diferents". Hay que tener en cuenta, sin embargo, las trabas que el régimen dictatorial ponía a la difusión de toda la información extranjera que tuviera el más mínimo eco revolucionario, factor que retrasó y obstaculizó la recepción de ideas en España.

${ }^{30}$ A pesar del esfuerzo del gobierno para maquillar las medidas represivas del Régimen, las sentencias del Tribunal de Orden Público provocan olas de protestas internacionales por el fusilamiento del comunista Julián Grimau (en 1963) y el del anarquista Puig Antich (en 1973), y por el proceso de Burgos (en 1970).
} 
Entre los millones de hombres y mujeres que colonizaron las playas del país, destaca especialmente la actitud de ellas, para establecer un flagrante contraste con las costumbres de las jóvenes españolas:

\begin{abstract}
“Aquellas mujeres, a quienes el subconsciente colectivo masculino tiñó de rubias y nacionalizó suecas, adoptaban con naturalidad maneras infrecuentes en las españolas: bebían, fumaban, acudían solas a bares o discotecas, mostraban sus afectos en público y tomaban el sol en las playas sin pudor, ataviadas con bañadores de dimensiones inverosímiles" (Lafuente, 2003: 187-188).
\end{abstract}

El choque del bikini minimalista con las normas que aún regían las playas y piscinas para preservar su moralidad desencadenó toda una serie de protestas de los guardianes de la decencia del país ${ }^{31}$. La juventud, sin embargo, tomaba nota de la nueva moda: la minifalda de la diseñadora Mary Quant provocó una revolución en la manera de vestir de las jóvenes españolas; la estética hippy (vestidos largos, ropas sencillas y sandalias), los vaqueros también para las chicas - y el anorak —en sustitución de la americana y la gabardina, que fueron arrinconadas junto con las corbatas - se convirtieron en símbolos de la indumentaria progre, que parecía marcar el final de toda una época ${ }^{32}$.

El otro gran elemento de identificación pública de los sectores jóvenes fue la música: el rock and roll, la nova cançó, la canción francesa y el folk fueron algunas de las nuevas propuestas que surgieron en la década de los sesenta.

Si bien la música yé-yé no implicaba más que una ruptura estética y acústica con la canción tradicional española, la nova cançó y el folk fueron más allá, cuestionando el establishment y, en especial, el aparato represivo de la dictadura. Tomando como modelo la canción protesta norteamericana (Bob Dylan, Joan Baez, Pete Seeger) y la canción de autor francesa (Georges Brassens, Léo Ferré), Lluís Serrahima reclama "canciones de ahora"33, y bajo la denominación de Els Setze Jutges (creada en 1961) se agrupan una serie de intel-lectuales que se proponen renovar la música catalana y hacerla símbolo de las reivindicaciones cívicas contra la dictadura.

El cambio de hábitos y actitudes respecto a las relaciones sexuales y la construcción de modelos y símbolos con los que identificarse — visibles en la indumentaria y en las preferencias musicales - hicieron los jóvenes de la generación de los sesenta un grupo

\footnotetext{
${ }^{31}$ Por ejemplo, en 1951 se llevó a cabo un Congreso Nacional de Moralidad en Playas y Piscinas en que varias organizaciones expresaron su preocupación por las actitudes que se veían en los espacios públicos. En 1954 se fundó la Asociación de la Cruzada Nacional de la decencia. Del nudismo, José P. Oliveras llegó a declarar, en su Guía médica sexual, que podía provocar la eliminación de los reflejos sexuales. Ver extractos de éste y otros manifiestos a Lafuente (2003: 189-191).

${ }^{32}$ Como explica Carles Santacana (1998: 185), la indumentaria había reflejado tradicionalmente las diferencias de clase, de estatus social, de procedencia geográfica o de hábitat, empezando por el rito de la puesta de largo, que significaba la presentación en sociedad de la joven aspirante a ingresar en el mundo adulto.

33 "Ens calen cançons d'ara" es el título del artículo que Serrahima publica en Germinàbit, precedente de Serra d'Or, donde reclamaba una renovación de la canción catalana, que no podía quedar anclada en el único bagaje de las letras tradicionales, que no se referían a la realidad coetánea. Véase Santacana (1998: 188).
} 
distintivo y contestatario ${ }^{34}$. Las nuevas formas de relación entre los sexos no estuvieron exentas, sin embargo, de conflictos y malentendidos provocados por el choque entre los antiguos valores y las nuevas creencias llevadas a extremos. La libertad como valor supremo generó, en muchas ocasiones, otro tipo de esclavitud, sobre todo en cuanto a la emancipación sexual.

Reflejo de esta sociedad en crisis es la coexistencia de prototipos femeninos tradicionales con nuevos modelos de feminidad, que a menudo recordaban instantáneas de antes de la guerra:

Los chicos y chicas de posguerra, fuera cual fuera la ideología de sus padres, habían vivido una infancia de imágenes más movidas y heterogéneas, donde junto a la abuela con devocionario y mantilla de toda la vida, aparecían otra clase de mujeres, desde la miliciana hasta la "vamp", pasando por la investigadora que sale con una beca al extranjero y la que da mítines. Las habían visto retratadas en las revistas, fumando con las piernas cruzadas, conduciendo un coche o mirando bacterias por un microscopio (Martín Gaite, 1987: 26) ${ }^{35}$.

Montserrat Roig observa estos contrastes en un artículo escrito en 1972 para un número extra de Cuadernos para el Diálogo, titulado “Algunas notas indiscretas sobre la mujer”. Para ella, la mujer joven del momento se debate entre tres papeles contradictorios: las madame Bovary, sentimentales y apasionadas, presuntas suicidas, dado el carácter inestable de sus afecciones; las George Sand, irritadas y reivindicativas, imitadoras del ideal masculino, que lo rehusan cuando lo encuentran; y, entre estos dos papeles, las excepciones determinadas y definidas por situaciones políticas azarosas y provisionales que exigen luchar por otros asuntos más urgentes y no inmediatos a la problemática de la mujer. Esta tercera vía, que ella ve personificada en activistas como Angela Davis o Bernardette Devlin, corre el riesgo de disolverse en el silencio con la llegada de la estabilidad, cuando se acabe el conflicto que las ha generado.

En realidad, la gran mayoría de las adolescentes españolas de la posguerra pertenecían a la categoría presidida por madame Bovary: eran las lectoras asiduas de novelas rosa y biografías de santas y reinas, las que soñaban "momentos inefables y únicos, quién sabe si por un insatisfecho deseo de supervivencia o notoriedad" (Roig, 1972: 17).

La otra cara de la moneda eran los productos que manipulaban la imaginería sexual del país, gracias al relajamiento de la censura oficial. Un cierto sector del cine empezaba a explotar la imagen de la mujer como objeto sexual — dentro de unos límites, sin embargo-, y preparaba el terreno para el fenómeno del destape que llegaría con la Transición ${ }^{36}$.

${ }^{34}$ La rebelión de la juventud se manifestó en espacios diferentes: las aulas universitarias, la oposición
antifranquista y, lo que es más significativo, los pisos de estudiantes emancipados de los padres, que
crearon un ambiente parauniversitario de tertulias y reuniones.
${ }^{35}$ De aquellas otras mujeres que durante la República habían luchado por la emancipación queda muy
poco en la primera posguerra. La niña topolino ya mencionada, "mimada, vacua y gastadora" (Martín
Gaite, 1987: 74), tampoco parecía una alternativa al rol tradicional imperante, por más que " aquel mismo
atolondramiento exhibido con desenfado podía considerarse - y era lo que más escamaba- como un
conato de enfrentamiento con otros modelos de conducta regidos por la prudencia y la sensatez" (Martín
Gaite, 1987: 79).
${ }^{36} \mathrm{M}$ a Ángeles Larumbe (2002: 148) enumera algunos títulos muy explícitos en este sentido: Chica fácil
al servicio del público, Tres suecas para tres Rodríguez, Demasiado bonita para ser honesta, etc. 
Así pues, durante los años sesenta el prototipo de adolescente elevada en nubes de color rosa comenzó a convivir con — o convertirse en, según los casos - el de la joven que leía Simone de Beauvoir e iba a bailar, fumaba, usaba un lenguaje agresivo y descartaba la faja, no quería tener más de dos hijos y consideraba "no sólo una antigualla sino una falta de cordura llegar virgen al matrimonio" (Martín Gaite, 1987: 217). Una revolución de tipo moral había comenzado, aunque los límites entre la burguesita sentimental y la mujer liberada quedaban aún muy difusos, con episodios de dudas y claudicaciones.

\section{Conclusiones}

Como hemos podido observar, aunque en la posguerra las mujeres no constituían un colectivo homogéneo (no era lo mismo pertenecer al bando de los vencidos que al de los vencedores, por ejemplo), el Régimen franquista dedicó gran parte de sus esfuerzos propagandísticos a educar a la población femenina en sus principios ideológicos y reducirla a un modelo de esposa y madre que debía recluirse en el hogar después del desorden que supusieron las avanzadas leyes de la II República y la situación excepcional provocada por la guerra civil, en la cual muchas mujeres tuvieron un papel activo y decisivo substituyendo a los hombres en la vida cotidiana en la retaguardia. Estos esfuerzos se canalizaron a través de la Sección Femenina de la Falange, dirigida por Pilar Primo de Rivera, pero éste no fue el único órgano que se encargó de llevar a cabo un proselitismo feroz contra cualquier esperanza de emancipación o realización de la mujer. En efecto, la Iglesia, el colectivo médico (especialmente, algunos profesionales de la Psicología) y los medios de comunicación de la época contribuyeron especialmente a intentar modelar el carácter de toda una generación de mujeres que debían ser felices en la maternidad y en una relación de silenciosa sumisión al hombre. En este panorama desolador, sin embargo, destacan los nombres de algunas pioneras que lograron romper con el orden establecido y ejercer su profesión en el mundo de las letras, el periodismo, la investigación, etc.

Con la irrupción del turismo en los años sesenta y los aires renovadores que tímidamente asoman en la península con el mayo del 68, se produce la confluencia de nuevos modelos femeninos y las imágenes tradicionales complacientes con el régimen. Asimismo, la actitud contestataria de la juventud, que encuentra canales de expresión a través de la música, la indumentaria y los movimientos universitarios, completa el conjunto de precedentes que generarán el cambio del modelo femenino, el cual va de la mano, a partir de mediados de los setenta, de la transformación política hacia la democracia.

Destacan, también, las excursiones que se organizaban en Perpiñán para ver las novedades prohibidas en este lado de los Pirineos, como Último tango en París, de Bertolucci. 


\section{BibLIOGRAFÍA}

- Alcalde, Carmen (1996): Mujeres en el franquismo. Barcelona: Flor del Viento.

- Blas, Isabel (1999): “Comunicación e información de mujeres y para mujeres". En: Asociación "Mujeres en la Transición Democrática": Las españolas en la Transición. De excluidas a protagonistas (1973-1982). Madrid: Biblioteca Nueva, pp. 325-427.

- Di Febo, Giuliana (1979): Resistencia y movimiento de mujeres en España 1936-1976. L'Hospitalet: Icaria.

- Díaz, Lorenzo (1994): La televisión en España (1949-1995). Madrid: Alianza Editorial.

- Fuente, Inmaculada de la (2002): Mujeres de la posguerra. De Carmen Laforet a Rosa Chacel: historia de una generación. Barcelona: Planeta.

- García-Nieto, M. Carmen (2000): “Trabajo y oposición popular de las mujeres durante la dictadura franquista”. En: Georges Duby y Michel Perrot (eds.): Historia de las mujeres en Occidente. vol. 5. Madrid: Santillana, pp. 722-735.

- Lafuente, Isaías (2003): Agrupémonos todas. La lucha de las españolas por la igualdad. Madrid: Aguilar.

- Larumbe, Mángeles (2002): Una immensa minoría. Influencia y feminismo en la transición. Zaragoza: Prensas Universitarias de Zaragoza.

- Martín Gaite, Carmen (1987): Usos amorosos de la postguerra española. Barcelona: Anagrama.

- Posa, Elena (1977): "Una dona portadora de valors eterns. La Sección Femenina 19341952”. En: Taula de canvi, no 5, mayo-junio, pp. 121-132.

- Roca, Jordi (1996): De la pureza a la maternidad: la construcción del género femenino en la postguerra española. Madrid: Ministerio de Educación y Cultura.

- Roig, Montserrat (1972): “Algunas notas indiscretas sobre la mujer”. En: Cuadernos para el diálogo, febrero, pp. 15-18.

- Santacana, Carles (1998): "La irrupció dels joves: la generació del 68”. En: Borja de Riquer (dir.): Història, política, societat $i$ cultura dels Països Catalans. De la dictadura a la democràcia (1960-1980), vol. 11. Barcelona: Enciclopèdia Catalana, pp. 182-199.

- Scanlon, Geraldine (1986): La polémica feminista en la España contemporánea. 18681974. Madrid: Ediciones Akal.

- Sopeña, Andrés (1996): La morena de la copla. La condición de la mujer en el reciente pasado. Barcelona: Roca Editorial.

- Soto, Juan (1996): Querida Elena Francis. Barcelona: Grijalbo. 